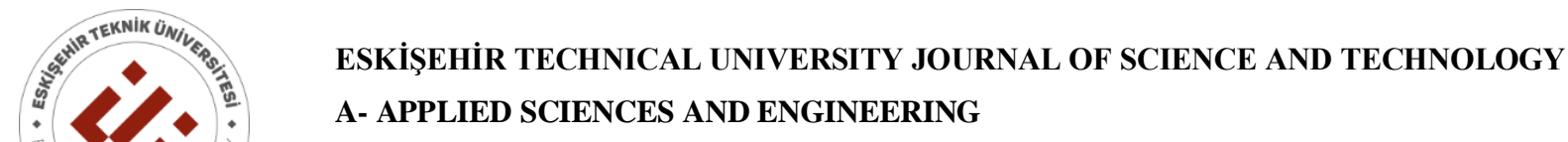

$2020,21(2)$, pp. 335 - 349, DOI: 10.18038/estubtda. 657085

\title{
MAGNETIC MESOPOROUS SILICA NANOCOMPOSITE DECORATED WITH HETEROPOLY TUNGSTIC ACID AS HIGHLY EFFICIENT AND STABLE CATALYST FOR BIODIESEL PRODUCTION
}

\author{
Beyhan ERDEM*, Kübra BİLGIN \\ Department of Chemistry, Faculty of Science and Arts, Bursa Uludağ University, 16059, Bursa, Turkey
}

\begin{abstract}
A multifunctional heterogeneous acid catalyst named as $\mathrm{spFe}_{3} \mathrm{O}_{4} @ \mathrm{SBA}-15 @ \mathrm{HPW}$ was prepared, which consists of versatile properties such as magnetic separability, high conversion efficiency and reusability. This catalyst was characterized by XRD, FT-IR, VSM, TEM and SEM/EDX techniques with respect to structural, morphological and magnetic properties. The catalyst showed higher catalytic activity than the commercial catalysts such as Amberlyst-15 and Dowex 50Wx4 and also heteropoly tungstic acid (HPW) alone in terms of conversion of oleic acid for biodiesel production by the esterification of oleic acid with methanol. The experimental data were correlated by pseudo-first-order homogeneous and Eley-Rideal heterogeneous models, and the results demonstrate the suitability of Eley-Rideal mechanism.
\end{abstract}

Keywords: Magnetic nanocomposite, Heterogeneous catalyst, Phosphotungstic acid, Biodiesel

\section{INTRODUCTION}

In recent years, attention has been given to biodiesel production, which is believed to have contributed to the prevention of environmental pollution, due to limited fossil fuel stocks. Today, biodiesel is usually obtained by triglycerides transesterification existed in vegetable oils or animal fats or by free fatty acids esterification. Homogeneous acid catalysts such as sulfuric and hydrochloric acids are the most commonly utilized catalysts for the esterification of free fatty acids. However, they have disadvantages such as corroding and fouling, complex neutralisation, difficulty in separation from the reaction medium and non-reusability. Besides, the utilization of solid acid catalyst having strong Brønsted acid sites not only offers advantages with respect to green chemistry but also disposes of disadvantages of liquid acids.

Heteropolyacids are composed of metal-oxygen octahedral structure unit and heteropolyanions. They have strong Brønsted acid character and they exhibit reversible multi-electron redox conversions, and high proton mobility in despite of specific ionic structure. For this reason, heteropolyacids effectively catalyze a broad array of reactions in both homogeneous and heterogeneous media [1]. A Keggin-type heteropolyacid has $\mathrm{H}_{8-\mathrm{x}} \mathrm{XM}_{12} \mathrm{O}_{40}$ structure. Here $\mathrm{X}$; is centre atom $\left(\mathrm{Si}^{4+}, \mathrm{P}^{5+}\right.$, etc. $)$, $\mathrm{x}$; is oxidation state, $\mathrm{M}$; is metal ion $\left(\mathrm{Mo}^{6+}, \mathrm{W}^{6+}\right)$. The use of $\mathrm{W}$ heteropolyacid (HPW) is more preferred in comparison with Mo, due to some advantages such as strong acidity, high thermal stability and low oxidation potential [2]. Heteropolyacid catalysts are very popular solid acids for acid catalyzed reactions, because their catalytic effects are very good. Heteropolyacids can be successfully applied in homogeneous catalysis since they dissolve well in water and polar organic liquids. However, in twophase reaction conditions, heteropolyacids are poorly soluble in the presence of low polar medium and have limited catalytic activity due to their low surface area and have no reusability [3]. There are several studies for increasing surface area and providing reusability in the literature [4-7]. Yue et al. synthesized mesoporous/macroporous $\mathrm{H}_{3} \mathrm{PW}_{12} \mathrm{O}_{40} / \mathrm{SiO}_{2}$ catalysts and investigated their activity in oxidative desulphurization and showed that they achieved highly improved catalytic efficiency due to their high surface areas [8]. Patil et al. synthesized biodiesel additives from fructose with

*Corresponding Author: gbeyhan@uludag.edu.tr

Received: 09.12.2019 Published: 15.06.2020 
$\mathrm{H}_{3} \mathrm{PW}_{12} \mathrm{O}_{40} / \mathrm{SBA}-15$ catalyst and reported that they obtained products with high yield [9]. Chen et al. synthesized $\mathrm{H}_{4} \mathrm{SiW}_{12} \mathrm{O}_{40} / \mathrm{SBA}-15$ catalyst and reported that they obtained high performance on oleic acid/methyl alcohol esterification reaction by using 1:40 mole ratio (oleic acid/methyl alcohol) and $0.5 \mathrm{~g}$ catalyst [1].

Filtration process, which is lucubratory and causes mass loss of catalyst, has been used in order to remove the used catalysts from the reaction medium. Magnetic separation is acknowledged to be speed, uncomplicated, environmentally-kind, and more practical manner than usual separation techniques [10]. Magnetic nanomaterials have been supported as a good candidate in recent times in terms of both resource conservation and environmental improvement due to the effective, low-cost and eco-friendly features. Especially superparamagnetic magnetite $\left(\mathrm{Fe}_{3} \mathrm{O}_{4}\right)$ nanoparticles are suitable for industrially important process like biodiesel production by virtue of the low production cost, easy preparation and admissible biocompatibility and since it avoids a secondary pollution and hard recyclability. Although not being magnetic interactions among the superparamagnetic nanoparticles due to particle's zero coercivity [11], they are still prone towards agglomeration to decrease their surface energy and are quite sensitive to the oxygen in the air. Therefore, it is crucial that magnetic nanoparticles are attached to the support structure. If this support is inorganic silica SBA-15 with meso sized (2 to $50 \mathrm{~nm}$ ) pores, the materials not only prevents the agglomeration but also improves the performance by enabling to functionalize of the silanol groups and providing large surface area. Basically, solvents are unnecessary for the separation stage, but are ultimately used for washing the catalyst before the following treatment. All these issues necessitate the application of magnetic nanoparticle reinforced catalysts, which is an interesting tool for green chemistry and probably for industrial applications [12]. According to the literature [13], the balance of the magnetism and activity of the catalyst is very difficult to control. Shi $\mathrm{Li}$ et al. reported that a high yield of methyl oleate formation was achieved from the reaction between oleic acid and methyl alcohol catalyzed by $\mathrm{Fe}_{3} \mathrm{O}_{4} @ \mathrm{SiO}_{2}-\mathrm{NH}_{2} / \mathrm{HPW} @ \mathrm{CS} / \mathrm{HPW}$ core@shell catalyst. They found that the magnetic catalyst showed outstanding catalytic performance and, more importantly, it can be easily regained and reused in consequence of their magnetic nature [10].

In this work, we designed multifunctional magnetic nanocomposite $\left(\mathrm{spFe}_{3} \mathrm{O}_{4} @ \mathrm{SBA}-15 @ \mathrm{HPW}\right)$ exhibiting magnetic property, abundant and easily accessible acid sites, and better catalytic performance in the esterification of oleic acid with methyl alcohol in comparison with commercial solid acid catalysts. Reaction conditions such as mole ratio and amount of catalyst were investigated, and reusability of the catalyst was also studied. Moreover, it was clarified that the esterification reaction was better correlated by the Eley-Rideal model than the pseudo-homogeneous one.

\section{EXPERIMENTAL}

\subsection{Synthesis of $\mathrm{spFe}_{3} \mathrm{O}_{4} @ \mathrm{SBA}-15 @ \mathrm{HPW}$}

Firstly, superparamagnetic $\mathrm{Fe}_{3} \mathrm{O}_{4}$ was pro fabricated via co-precipitation method. For that, $5.4 \mathrm{~g}$ of $\mathrm{FeCl}_{3} \cdot 6 \mathrm{H}_{2} \mathrm{O}$ and $1.99 \mathrm{~g}$ of $\mathrm{FeCl}_{2} \cdot 4 \mathrm{H}_{2} \mathrm{O}$ were dissolved together in $0.5 \mathrm{M} 25 \mathrm{~mL} \mathrm{HCl}$ solution. The solution was added dropwise to $1.5 \mathrm{M} 250 \mathrm{~mL} \mathrm{NaOH}$ in a flask, the mixture was stirred under nitrogen gas at $80{ }^{\circ} \mathrm{C}$ for $60 \mathrm{~min}$. The obtained product was decanted with magnetic force and washed with deionized water and then dried at $50{ }^{\circ} \mathrm{C}$ under vacuum.

Secondly, $\mathrm{spFe}_{3} \mathrm{O}_{4} @ \mathrm{SBA}-15$ was prepared by hydrothermal synthesis method. $4 \mathrm{~g}$ of Pluronic 123 (poly (ethylene glycol)-block-poly (propylene glycol)-block-poly (ethylene glycol)) was dissolved in $140 \mathrm{~mL}$ of $0.5 \mathrm{M} \mathrm{HCl}$ solution. $2 \mathrm{~g}$ of $\mathrm{spFe}_{3} \mathrm{O}_{4}$ got involved in reactor including $\mathrm{P} 123 / \mathrm{HCl}$ solution at $40{ }^{\circ} \mathrm{C}$ and the suspension was stirred for $1 \mathrm{~h}$. Then, $9 \mathrm{~mL}$ of TEOS was added into the mixture drop by drop and reaction was kept on at $40{ }^{\circ} \mathrm{C}$ for 24 hours. It was transferred to Teflon cup and condensation 
was achieved at 24 hours in oven at $100{ }^{\circ} \mathrm{C}$. Resultant product was separated magnetically and dried in oven at $80{ }^{\circ} \mathrm{C}$. After drying process, solid phase was calcined at $500{ }^{\circ} \mathrm{C}$ for $6 \mathrm{~h}$ under nitrogen gas.

Finally, $\mathrm{spFe}_{3} \mathrm{O}_{4} @ \mathrm{SBA}-15$ was functionalized with 12-phosphotungstic acid as HPW source by impregnation method. $1 \mathrm{~g}$ of calcined $\mathrm{spFe}_{3} \mathrm{O}_{4} @ \mathrm{SBA}-15$ was stirred in $30 \% \mathrm{HPW}$ in methyl alcohol solution under nitrogen gas for overnight. After being evaporated at $60{ }^{\circ} \mathrm{C}$, it was dried in oven at 60 ${ }^{\circ} \mathrm{C}$ under vacuum and calcined at $130{ }^{\circ} \mathrm{C}$ for 90 min under nitrogen atmosphere. The resultant material was called as $\mathrm{spFe}_{3} \mathrm{O}_{4} @ \mathrm{SBA}-15 @ \mathrm{HPW}$. A summary of the synthesis procedure is presented in Scheme 1.

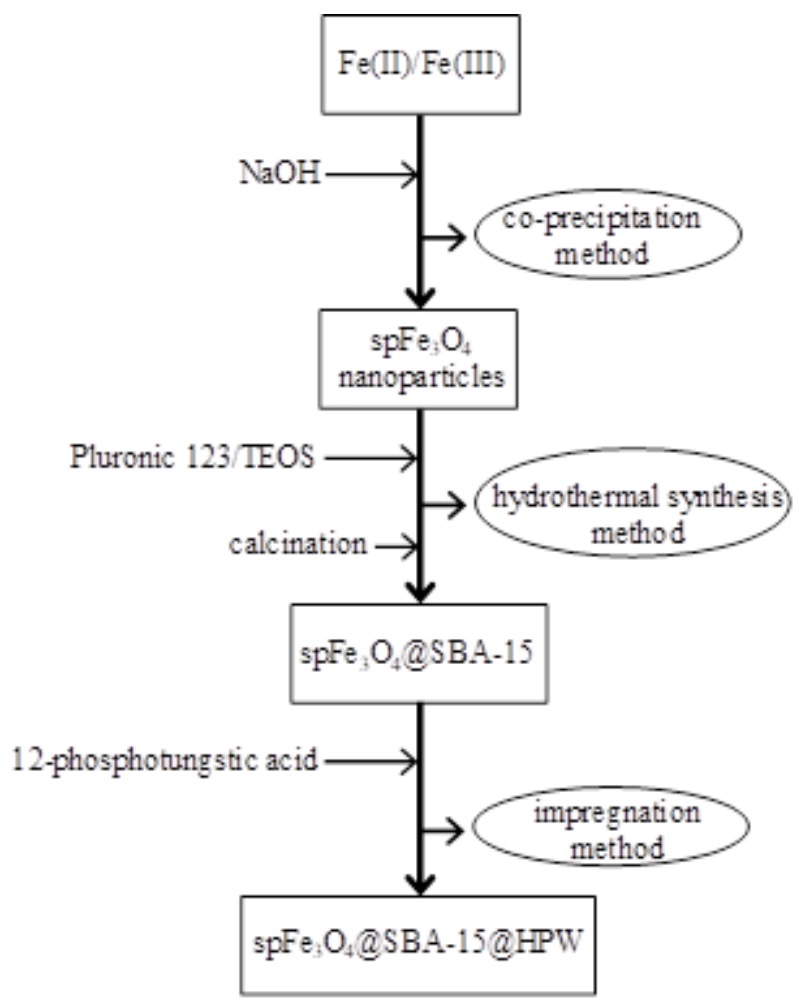

Scheme 1. A flow chart of the synthesis procedure for $\mathrm{spFe}_{3} \mathrm{O}_{4} @ \mathrm{SBA}-15 @ \mathrm{HPW}$ nanocomposite

\subsection{Characterization of $\mathrm{spFe}_{3} \mathrm{O}_{4} @ \mathrm{SBA}-15 @ \mathrm{HPW}$}

Powder X-ray diffraction (XRD) patterns were obtained to identify the phase structure by using Rigaku Ultima-IV X-ray diffraction device with a $\mathrm{CuK}_{\alpha}$ irradiation. Samples were scanned in the range of diffraction angles $2 \theta=0.5-3^{\circ}$ for low-angle and $2 \theta=10-80^{\circ}$ for high-angle to determine the morphology of the novel material. Structure and size of material were examined via FEI Tecnai transmission electron microscopy (CTEM) with an accelerating voltage of range 20-120 kV to reduce electron beam damage in samples. Surface morphology was investigated with physical adsorption studies (BET/BJH method) by Quantachrome Autosorb-6 to obtain pore size, pore size distribution, and surface area, respectively. Magnetic characterization of the material was realized with vibrating sample magnetometer (VSM, Cryogenic Limited PPMS) at room temperature. The components of the nanoparticles were analyzed with high resolution at $30 \mathrm{kV}$ by using energy dispersive $\mathrm{X}$-ray spectrometer (EDX, SEM VEGA II XMU, TECAN). FT-IR spectra taken with Perkin Elmer-UATR Two series infrared spectroscopy were analyzed. 


\subsection{Catalytic Reaction}

The catalytic performance of $\mathrm{spFe}_{3} \mathrm{O}_{4} @ \mathrm{SBA}-15 @ \mathrm{HPW}$ was tested by esterification of oleic acid with methyl alcohol. Firstly, the reaction was carried out at variable mole ratio of methyl alcohol to oleic acid $(10: 1,20: 1,30: 1)$ to determine optimum ratio, while maintaining amount of catalyst $250 \mathrm{mg}$ and temperature $60{ }^{\circ} \mathrm{C}$. Secondly, the amount of catalyst was optimized by using different amounts of catalyst $(125,250,500 \mathrm{mg})$ for the esterification of oleic acid with methyl alcohol (20:1 methyl alcohol oleic acid ratio, $60{ }^{\circ} \mathrm{C}$ ). Finally, the catalytic activity of $\mathrm{spFe}_{3} \mathrm{O}_{4} @ \mathrm{SBA}-15 @ \mathrm{HPW}$ was compared with commercially available acid catalysts such as Amberlyst-15, Dowex 50Wx4, and 12phosphotungstic acid alone as HPW source. The catalyst was recycled in order to test its activity as well as stability. After being separated from the reaction mixture with a magnet, washed with methanol followed by drying, $\mathrm{spFe}_{3} \mathrm{O}_{4} @ \mathrm{SBA}-15 @ \mathrm{HPW}$ was reused as catalyst four times. In addition to these experimental studies, the acid capacity of $\mathrm{spFe}_{3} \mathrm{O}_{4} @ \mathrm{SBA}-15 @ \mathrm{HPW}$ nanocomposite was measured by means of acid-base titration using sodium chloride $(2 \mathrm{M})$ as ion-exchange agent, and very high acid exchange value $\left(5.500 \mathrm{mmol} \mathrm{g}^{-1}\right)$ with \pm 0.036 standard error was obtained.

\section{RESULTS AND DISCUSSION}

\section{1. Catalyst Characterization}

The FTIR spectra of spFe $\mathrm{O}_{4} @ \mathrm{SBA}-15, \mathrm{spFe}_{3} \mathrm{O}_{4} @ \mathrm{SBA}-15 @ \mathrm{HPW}$ and used-spFe $\mathrm{O}_{4} @ \mathrm{SBA}-$ 15@HPW nanocomposites were shown in Figure 1. According to the literature, the four main peaks for bulk HPW are demonstrated as follows: $1080 \mathrm{~cm}^{-1}$ for P-O (in the central $\mathrm{PO}_{4}$ tetrahedron), around $980 \mathrm{~cm}^{-1}$ for $\mathrm{W}=\mathrm{O}$ ( in the exterior $\mathrm{WO}_{6}$ octahedron terminal oxygen atoms forming of $\mathrm{W}=\mathrm{O}$ band), $890 \mathrm{~cm}^{-1}$ for $\mathrm{W}_{-} \mathrm{O}_{\mathrm{c}}-\mathrm{W}$ (in $\mathrm{W}_{3} \mathrm{O}_{10}$ subunits corner shared octahedral bridging oxygen atoms $\mathrm{W}-\mathrm{O}-\mathrm{W}$ ), $800 \mathrm{~cm}^{-1}$ for $\mathrm{W}-\mathrm{O}_{\mathrm{e}}-\mathrm{W}$ (in $\mathrm{W}_{3} \mathrm{O}_{10}$ subunits edge shared bridging oxygen atoms $\mathrm{W}-\mathrm{O}-\mathrm{W}$ ) suggesting Keggin structure of 12-phosphotungstic acid compound [8, 9, 14, 15]. Characteristic peaks of SBA-15 are observed as: $1082-1165$ and $801 \mathrm{~cm}^{-1}$ for the asymmetric and symmetric stretching vibrations of $\mathrm{Si}-\mathrm{O}-\mathrm{Si}$, recpectively, and $960 \mathrm{~cm}^{-1}$ for the stretching vibration of $\mathrm{Si}-\mathrm{OH}[1,9]$. In addition, Fe-O stretching vibration is detected by the peak at $593 \mathrm{~cm}^{-1}$ [10]. For the spectrum of $\mathrm{spFe}_{3} \mathrm{O}_{4} @ \mathrm{SBA}-15$, the peaks at 958 , and $798 \mathrm{~cm}^{-1}$ and $1080-1050 \mathrm{~cm}^{-1}$ are ascribed to SBA-15 and the peak at $572 \mathrm{~cm}^{-1}$ belongs to $\mathrm{Fe}_{3} \mathrm{O}_{4}$, and the last two bands were observed for all samples. For the spectrum of $\mathrm{spFe}_{3} \mathrm{O}_{4} @ \mathrm{SBA}-15 @ \mathrm{HPW}$ composite, band of $\mathrm{W}-\mathrm{O}_{\mathrm{e}}-\mathrm{W}$ was observed at $778 \mathrm{~cm}^{-1}$ with significant shift due to the effect of symmetric stretching mode of Si-O-Si [9] that could be evidence the strong interaction between HPW and SBA-15. However, the peak of SBA-15 at $958 \mathrm{~cm}^{-1}$ [15] belonging to the stretching vibration of Si-OH remained within band of $\mathrm{W}=\mathrm{O}$ at $973 \mathrm{~cm}^{-1}$. In addition, the band at $884 \mathrm{~cm}^{-1}$ ascribes to $\mathrm{W}-\mathrm{O}_{\mathrm{c}}-\mathrm{W}$ [16]. The broad band between $3650-3000 \mathrm{~cm}^{-1}$ with a shoulder at 1625 $\mathrm{cm}^{-1}$ were observed for all spectra, ascribing plausibly to bending and stretching vibrations of bridging hydroxyl, respectively, due to interaction between surface silanol groups of SBA-15 and HPW anions [17]. These results supported that the HPW has been successfully impregnated into the SBA-15. The low and wide angle X-ray diffraction (XRD) patterns of $\mathrm{spFe}_{3} \mathrm{O}_{4} @ \mathrm{SBA}-15 @ \mathrm{HPW}$ nanocomposite are shown in Figure 2. The presence of only (100) diffraction peak (inset of Figure 2), which is resulted in the decrease in the degree of order due to the HPW particles inside the mesoporous channels of nanocomposite, indicates that the magnetic mesoporous silica remains intact after HPW loading [18]. Wide-angle XRD is used to identify the crystalline phase of the samples. Figure 2 shows the XRD patterns of nanocomposite before and after HPW loading. The emerging of the reflection characteristic of crystalline HPW is most likely due to the nucleation of each Keggin unit. The main Keggin unit is structurally preserved over support, however the lower area of $\mathrm{spFe}_{3} \mathrm{O}_{4} @ \mathrm{SBA}-15$ support does not permit the stabilization of high concentrations of isolated and/or low dimensional polyoxometallate clusters along the mesopores, $\mathrm{spFe}_{3} \mathrm{O}_{4} @ \mathrm{SBA}-15$ enables the formation of large HPW crystallites, which are nonuniformly distributed over the external surface. This result is confirmed with the literatures $[19,20]$. 


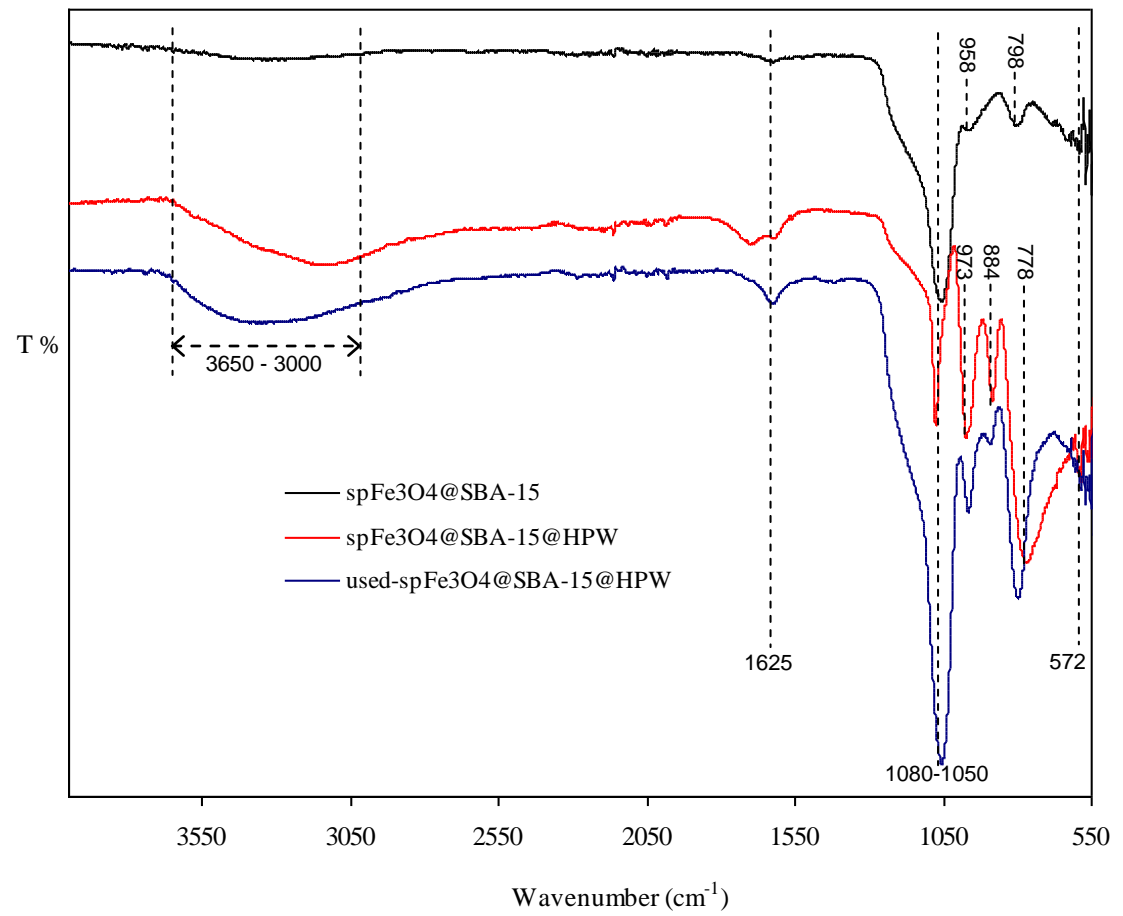

Figure 1. FT-IR spectra of $\mathrm{spFe}_{3} \mathrm{O}_{4} @ \mathrm{SBA}-15, \quad \mathrm{spFe}_{3} \mathrm{O}_{4} @ \mathrm{SBA}-15 @ \mathrm{HPW}, \quad$ and used-spFe $\mathrm{O}_{4} @ \mathrm{SBA}-15 @ \mathrm{HPW}$ nanocomposites

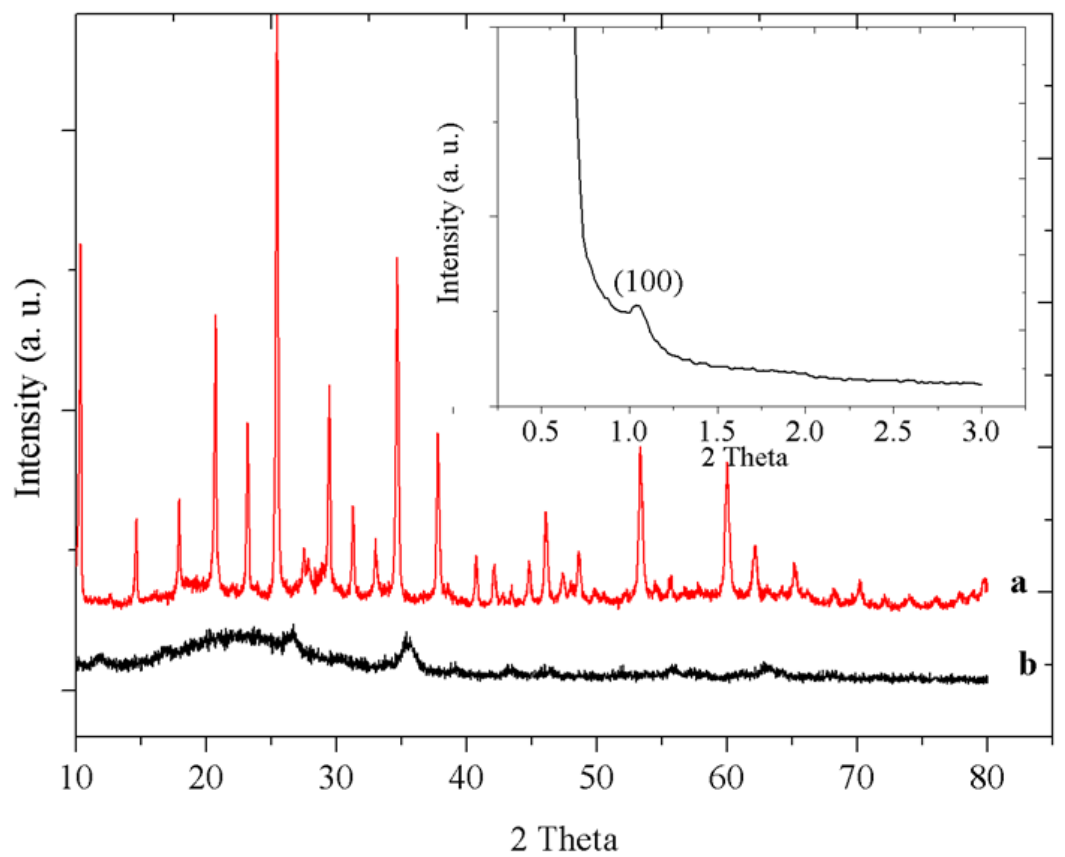

Figure 2. High angle X-ray diffraction patterns of spFe $\mathrm{O}_{4} @ \mathrm{SBA}-15 @ \mathrm{HPW}$ (a), $\mathrm{spFe}_{3} \mathrm{O}_{4} @ \mathrm{SBA}-15$ (b), and low angle X-ray diffraction patterns of $\mathrm{spFe}_{3} \mathrm{O}_{4} @ \mathrm{SBA}-15 @ \mathrm{HPW}$ nanocomposite (inset) 
The $\mathrm{N}_{2}$-adsorption/desorption isotherms and BJH pore-size distribution of $\mathrm{spFe}_{3} \mathrm{O}_{4} @ \mathrm{SBA}-15 @ \mathrm{HPW}$ nanocomposite are presented in Figure 3. The nanocomposite shows type of IV isotherm and the pore analysis, as shown on the inset of Figure 3, discloses a broad size distribution ascribed to both open and plugged mesopores. The desorption branch extended to a lower relative pressure indicating the plugged hexagonal template structure and the formation of some narrower pores [21]. Besides, $\mathrm{spFe}_{3} \mathrm{O}_{4} @ \mathrm{SBA}-15 @ \mathrm{HPW}$ nanocomposite has step-wise desorption isotherm demonstrating the bimodal porosity, that is: $\mathrm{spFe}_{3} \mathrm{O}_{4} @ \mathrm{SBA}-15 @ \mathrm{HPW}$ contains both open and encapsulated mesopores which empty at lower pressure than the open pores of similar size [22]. The average open pore size of approximately $6.3 \mathrm{~nm}$ derived from $\mathrm{BJH}$ method is in good agreement with that of transmission electron microscopy measurement. However, the formation of different sized pores can be arised from the wadding of HPW units both inside and the outside the channels [3]. According to the textural properties of the sample based on $\mathrm{N}_{2}$-sorption such as surface area $\left(50.8 \mathrm{~m}^{2} \mathrm{~g}^{-1}\right)$ and pore volume $(0.04$ $\mathrm{cm}^{3} \mathrm{~g}^{-1}$ ), it was concluded that the low specific surface area and pore volume could be associated with the agglomeration of HPW molecules especially over the external surface of the material causing pore blockage as seen in the XRD results.

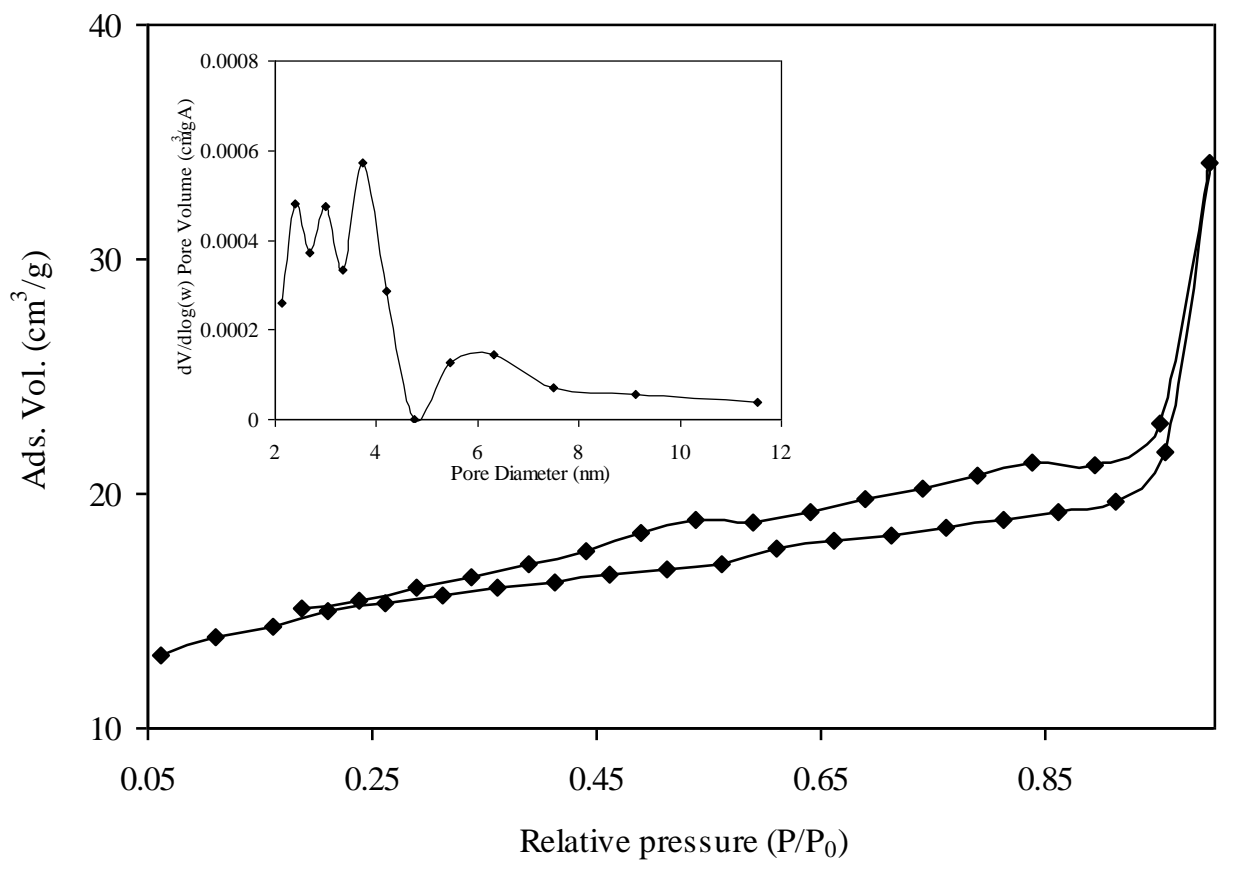

Figure 3. $\mathrm{N}_{2}$-adsorption/desorption isotherm and pore size distribution (inset) of spFe $\mathrm{O}_{4} @ \mathrm{SBA}-15 @ \mathrm{HPW}$ nanocomposite

Apart from BET measurements, the porous nature of the material is clearly observed from TEM analysis. The TEM image of $\mathrm{spFe}_{3} \mathrm{O}_{4} @ \mathrm{SBA}-15 @ \mathrm{HPW}$ nanocomposite is depicted in Figure 4. According to the well-resolved contrast characteristics of mesoporous magnetic silica support, we can say that the long-range ordered arrangement of the channels in the silica matrix is preserved after loading of HPW. However, the small dark spots and the larger dark areas over the channels could be ascribed to HPW particles probably located into the support channels and HPW agglomerates on the external surface, respectively [23]. It can be estimated from Figure 4 that the open pore size of $\mathrm{spFe}_{3} \mathrm{O}_{4} @ \mathrm{SBA}-15 @ \mathrm{HPW}$ nanocomposite is about $6.25 \mathrm{~nm}$, which is consistent with the BJH result. The composition of the $\mathrm{spFe}_{3} \mathrm{O}_{4} @ \mathrm{SBA}-15 @ \mathrm{HPW}$ nanocomposite is obtained from EDX analysis, which is presented in Figure 5. The EDX spectrum of the nanocomposite confirms the presence of $\mathrm{Fe}$, $\mathrm{Si}, \mathrm{W}$ and $\mathrm{O}$ elements, which validates the purity of the material [24]. It is significant that the nanocomposite should have superparamagnetic properties to realize rapid separation in a magnetic field [25]. Although the saturation magnetization $\left(\mathrm{M}_{\mathrm{s}}\right)$ of the nanocomposite is about $0.06 \mathrm{emu} / \mathrm{g}$ (Figure 6), it can still respond to an external magnetic field. According to Figure 6, the magnetization 
Erdem and Bilgin / Eskişehir Technical Univ. J. of Sci. and Tech. A-Appl. Sci. and Eng.21 (2)- 2020

curve of $\mathrm{spFe}_{3} \mathrm{O}_{4} @ \mathrm{SBA}-15 @ \mathrm{HPW}$ nanocomposite shows superparamagnetic behavior due to the negligible hysteresis, remanence $\left(\mathrm{M}_{\mathrm{r}}\right)$ and coercivity. Also spFe $\mathrm{O}_{4} @ \mathrm{SBA}-15 @ \mathrm{HPW}$ nanocomposite has $\mathrm{M}_{\mathrm{r}} / \mathrm{M}_{\mathrm{s}}$ ratio of 0.06 , which is defined as the squareness ratio of hysteresis loop and which should be smaller than 0.1 for superparamagnetic particles [26].

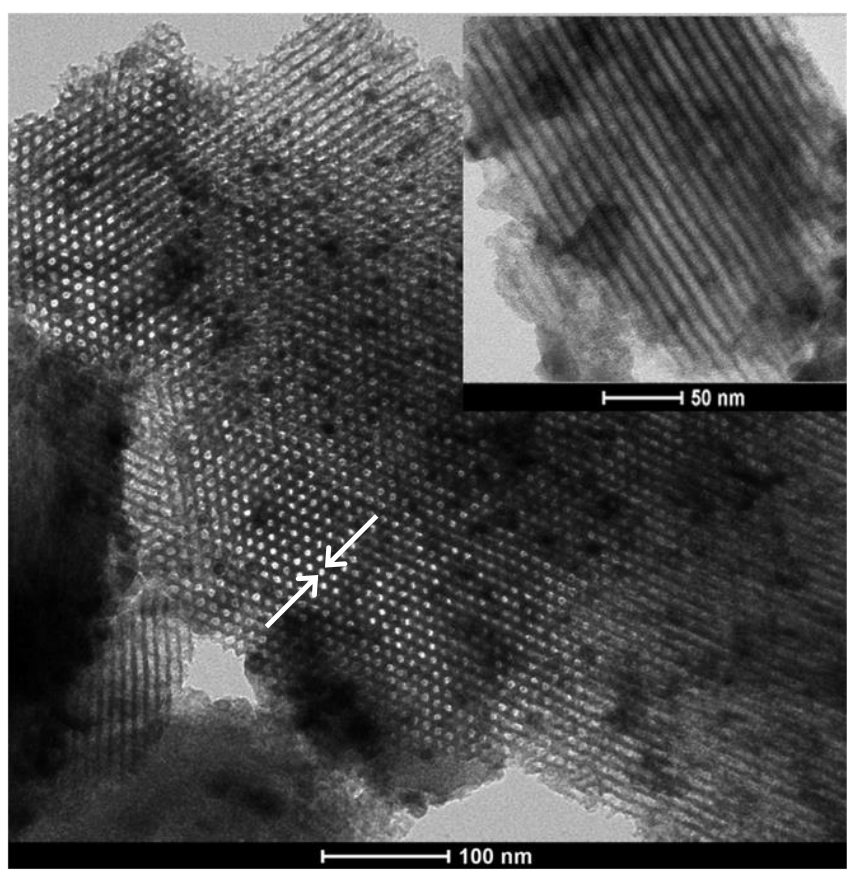

Figure 4. TEM micrograph of $\mathrm{spFe}_{3} \mathrm{O}_{4} @ \mathrm{SBA}-15 @ \mathrm{HPW}$ nanocomposite

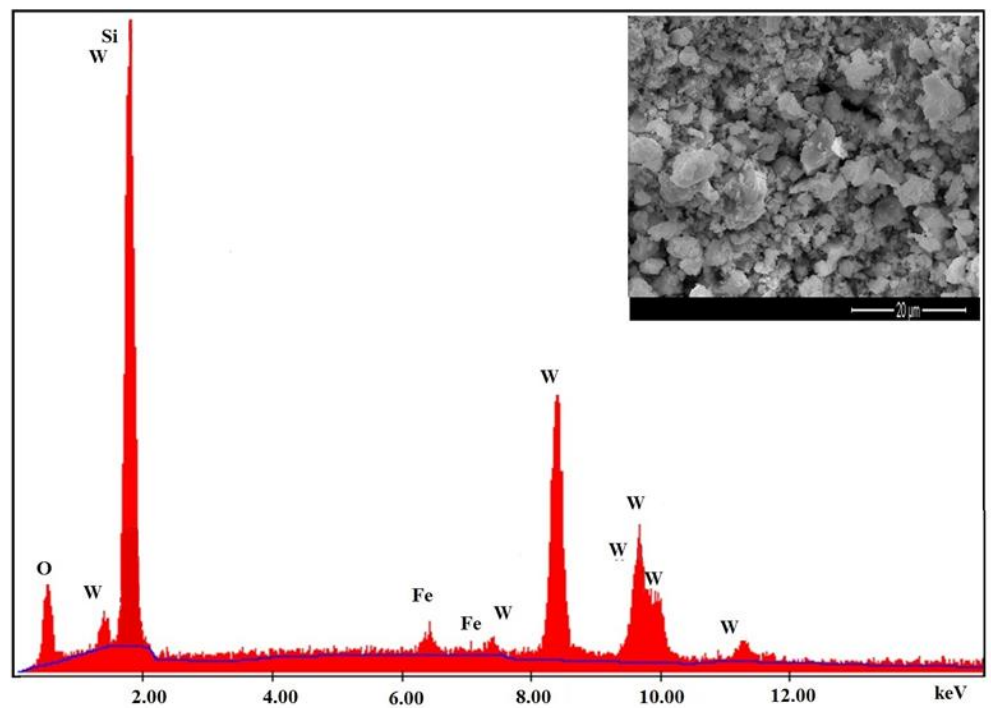

Figure 5. EDX spectrum of spFe $\mathrm{O}_{4} @ \mathrm{SBA}-15 @ \mathrm{HPW}$ nanocomposite 


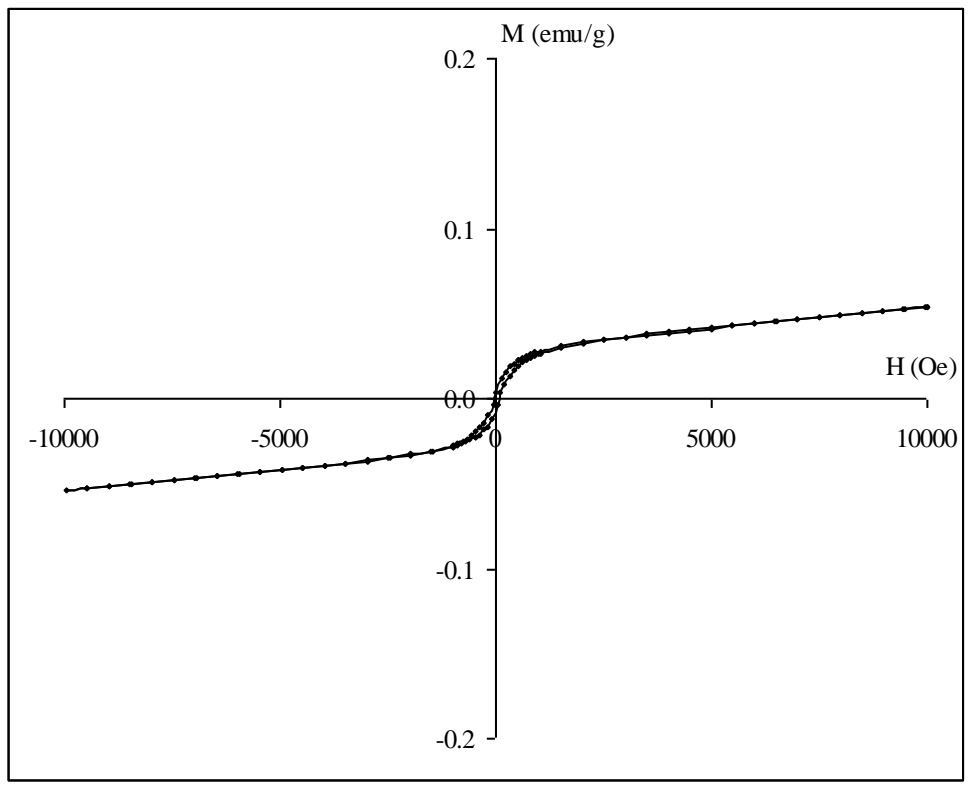

Figure 6. VSM analysis of $\mathrm{spFe}_{3} \mathrm{O}_{4} @ \mathrm{SBA}-15 @ \mathrm{HPW}$ nanocomposite

\section{2. Catalytic Experiments}

Since the esterification reaction is an equilibrium-limited reaction, the alcohol is usually taken in excess to favor the forward reaction. The synthesized nanocomposite was tested in esterification reaction which was carried out with 20:1 mole ratio of methyl alcohol to oleic acid by using $250 \mathrm{mg}$ of catalyst for $24 \mathrm{~h}$ reaction time at $60{ }^{\circ} \mathrm{C}$ according to the literature [1, 10]. The methyl oleate yield reaches to $54.6 \%$ (seen Figure 7) at the reaction time of $60 \mathrm{~min}$, indicating that the reaction rapidly occurs and the methyl oleate yield further increased to $92.7 \%$ and $95.5 \%$ with increasing reaction time to $6 \mathrm{~h}$ and $24 \mathrm{~h}$, respectively. Based on this, the esterification reaction was carried out with several mole ratio of methyl alcohol to oleic acid by using $250 \mathrm{mg}$ of catalyst for $60 \mathrm{~min}$ reaction time at $60{ }^{\circ} \mathrm{C}$ to investigate the effect of methanol/oleic acid ratio on the reaction conversion. As seen in Figure 8, the reaction conversions reached to $44.4 \%, 54.6 \%$ and $41.8 \%$ at 10:1, 20:1, and 30:1 methanol/oleic acid mole ratios, respectively. With further increase in mole ratio, no further increase of ester yield was observed. However, the reaction conversions at both 10:1 and 30:1 mole ratio were lower than at 20:1 mole ratio even if just a bit difference. Since the large parts of the active sites of the nanocomposite were occupied by the extreme methanol, the interaction between the oleic acid and catalyst could be prevented. According to the literature, the decreasing of reaction conversion at higher mole ratios was obtained when the reaction rate increases linearly with one reactant while nonlinearly with another reactant in esterification reactions. Hence mole ratio of 20:1 was selected for obtaining the highest conversion. When the result was compared with the literature, it was seen that a good efficiency could be obtained by using $\mathrm{spFe}_{3} \mathrm{O}_{4} @ \mathrm{SBA}-15 @ \mathrm{HPW}$ as catalyst under aforementioned reaction conditions which provide the highest conversion [27].

The impact of catalyst dosage was investigated at $60{ }^{\circ} \mathrm{C}$, for $60 \mathrm{~min}$ and $20: 1 \mathrm{methanol} / \mathrm{oleic}$ acid ratio. According to the results, optimal amount of catalyst was determined as $250 \mathrm{mg}$ for above mentioned reaction conditions. As seen in Figure 9, the reaction conversion increased as the amount of catalyst increased. However, the conversion was not increased when the catalyst was used in excess of $250 \mathrm{mg}$ of catalyst mass. When the amount of catalyst increased from $125 \mathrm{mg}$ to $250 \mathrm{mg}$, the active sites increased and therefore it can be said that the reaction rapidly occurred. However, if the amount of catalyst increases more, conversion \% decreases due to blocking of the active sites. 
Erdem and Bilgin / Eskişehir Technical Univ. J. of Sci. and Tech. A-Appl. Sci. and Eng.21 (2)- 2020

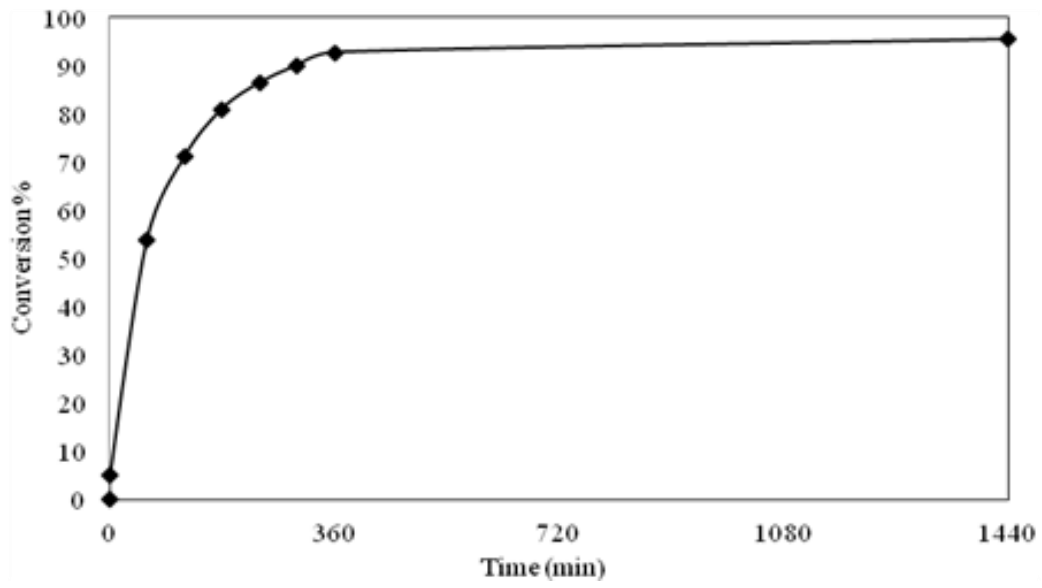

Figure 7. Conversion of oleic acid versus time $\left(60^{\circ} \mathrm{C}, 20: 1\right.$ mole ratio of methyl alcohol:oleic acid, $0.25 \mathrm{~g} \mathrm{spFe}_{3} \mathrm{O}_{4} @ \mathrm{SBA}$ 15@HPW nanocomposite)

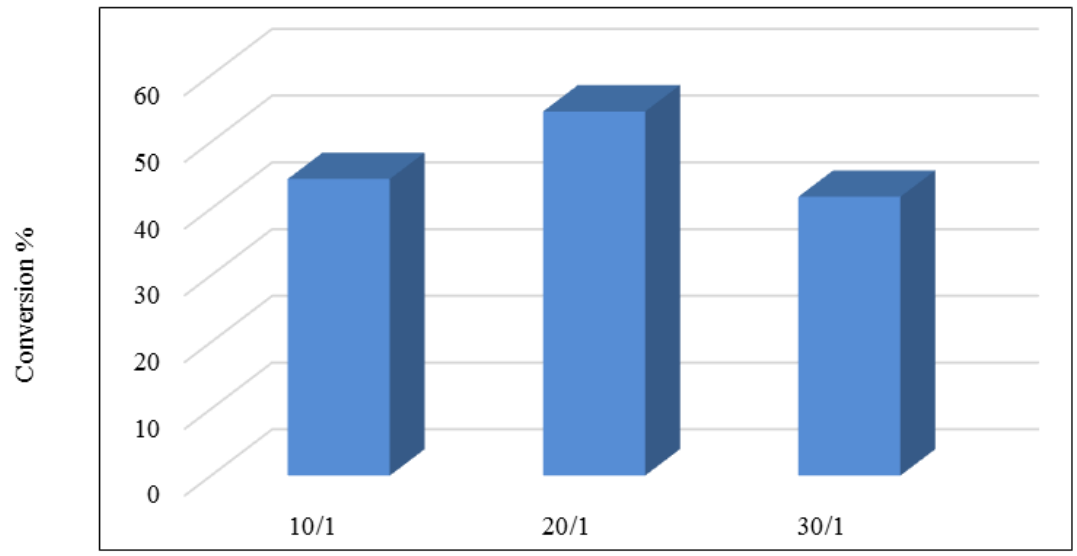

Mole Ratio (alcohol/acid)

Figure 8. Effect of mole ratio on the conversion of oleic acid (catalyst amount: $0.25 \mathrm{~g}$, temperature: $60{ }^{\circ} \mathrm{C}$, reaction time: 60 $\min$ )

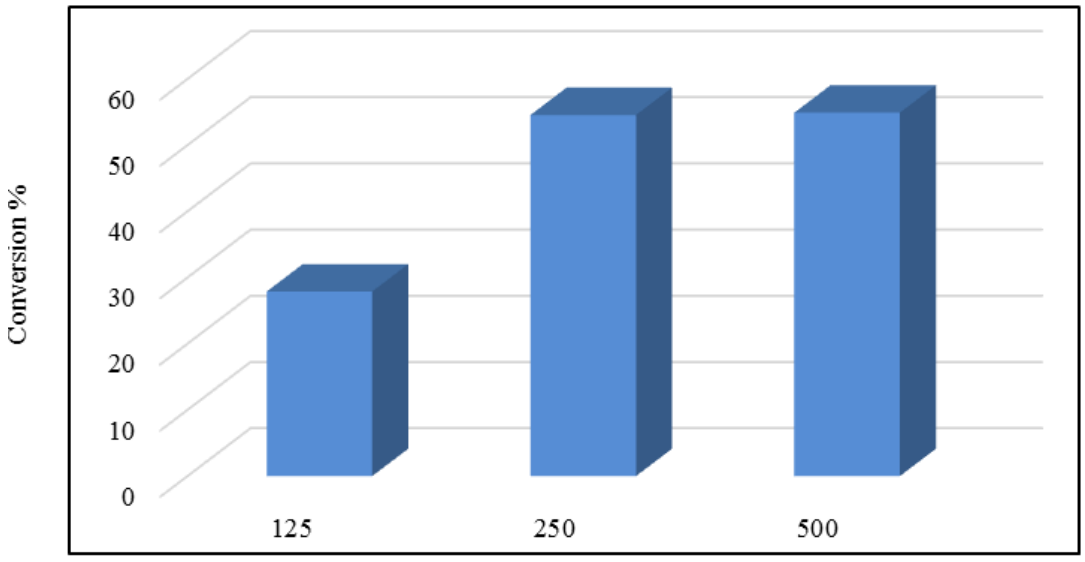

Amount of catalysts (mg)

Figure 9. Effect of amount of $\mathrm{spFe}_{3} \mathrm{O}_{4} @ \mathrm{SBA}-15 @ \mathrm{HPW}$ on the conversion of oleic acid (reaction conditions: mole ratio alcohol/acid $20: 1$, reaction temperature $60^{\circ} \mathrm{C}$, reaction time $60 \mathrm{~min}$ ) 
To compare the activity of $\mathrm{spFe}_{3} \mathrm{O}_{4} @ \mathrm{SBA}-15 @ \mathrm{HPW}$ catalyst with various catalyst including commercial (Amberlyst-15 and Dowex 50Wx4; Fluka) and HPW catalysts alone, the esterification reactions were carried out at $60{ }^{\circ} \mathrm{C}$, for $24 \mathrm{~h}, 20: 1$ (methyl alcohol/oleic acid) ratio and $250 \mathrm{mg}$ of catalysts (Figure 10). While $\mathrm{spFe}_{3} \mathrm{O}_{4} @ \mathrm{SBA}-15 @ \mathrm{HPW}$ provided a high conversion (95.5\%), purchased Amberlyst (61.7\%) and Dowex (48.2 \%) catalysts were not much active towards the esterification of oleic acid with methanol, as seen at Figure 10. The enhanced catalytic activity can be ascribed to the high surface area and a huge amount of active acidic sites. Moreover, it can be said that catalytic activities of $\mathrm{spFe}_{3} \mathrm{O}_{4} @ \mathrm{SBA}-15 @ \mathrm{HPW}(95.5 \%)$ and HPW $(95.3 \%)$ alone are almost the same, which indicates the catalytic activity is due to HPW. Normally, homogeneous acid catalysts are more successful than heterogeneous acid catalysts due to the lack of sorptional and diffusional limitations. However, homogeneous acid catalysts cause corrosion problems and have inability to reuse. spFe $\mathrm{O}_{4} @ \mathrm{SBA}-15 @ \mathrm{HPW}$ nanocomposite not only has the high catalytic efficiency for the esterification of oleic acid with methanol, which can be candidate catalyst for the concentrated HPW, but also it can be easily separated from the reaction mixture with the help of external magnet.

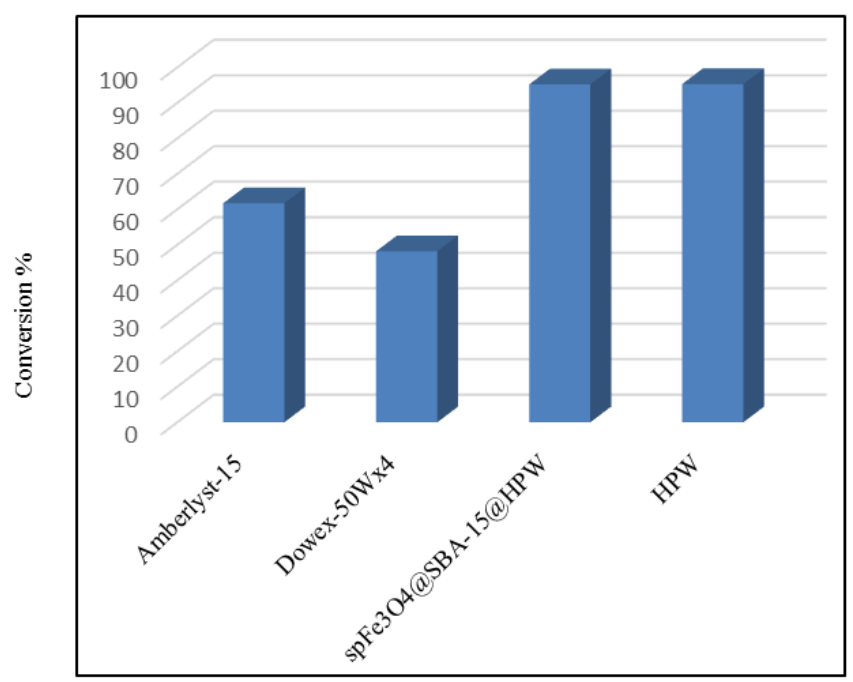

Figure 10. Comparison of catalytic activity of spFe $\mathrm{O}_{4} @ \mathrm{SBA}-15 @ \mathrm{HPW}$ with Amberlyst-15, Dowex 50WX4, and HPW alone.

The reusability test of $\mathrm{spFe}_{3} \mathrm{O}_{4} @ \mathrm{SBA}-15 @ \mathrm{HPW}$ nanocomposite was correlated four times. During the four successive runs, the conversion of oleic acid at the sixth hours decreased in the $92.7 \%-88.1 \%$ $86.4 \%-78.7 \%$ order. This may be attributed to the partial leaching of HPW species. Even so, the yield keeps relatively stable, suggesting the $\mathrm{spFe}_{3} \mathrm{O}_{4} @ \mathrm{SBA}-15 @ \mathrm{HPW}$ nanocomposite has durability in the reaction. In addition, the FT-IR spectrum of the used-spFe $\mathrm{O}_{4} @ \mathrm{SBA}-15 @ \mathrm{HPW}$ (Figure 1) shows no change basically except for the decreasing of HPW peaks (especially at 973, 884 and 778 $\mathrm{cm}^{-1}$ ). Due to the overcharging of HPW, these species could form multilayer and aggregated crystalline phase may have occurred as verified by high angle XRD results. This prevents the reactant molecules from reacting with the active sites.

When the concentration of one of the reactants is taken in large excess, the rate of reaction depends on the other reactant the concentration of which is lower. So, the pseudo-first order kinetic model can be proposed for these reactions and the rate equation can be defined as a function of reaction conversion (X) as follows:

$$
-\ln (1-X)=k t
$$

$\mathrm{X}$ presents the conversion of oleic acid $\left(\mathrm{C}_{0}-C\right) / \mathrm{C}_{0}$ and $\mathrm{k}$ refers to the first order rate constant. Whether the kinetic data fits to the pseudo-first order kinetic model is checked by correlation coefficients. At the same time, providing that the rate determining step is the surface reaction step, Eley-Rideal 
mechanism is proposed for oleic acid-methyl alcohol esterification reaction, in which adsorbed oleic acid reacts with methyl alcohol in the reaction medium, and the kinetic data were also controlled for Eley-Rideal mechanism with correlation coefficients. According to this mechanism, initial reaction rate is described as:

$$
-\mathrm{r}_{\mathrm{OA}_{0}}=\frac{\mathrm{kC}_{\mathrm{OA}_{0}} \mathrm{C}_{\mathrm{M}_{0}}}{\left(1+\mathrm{K}_{\mathrm{A}} \mathrm{C}_{\mathrm{M}_{0}}\right)}
$$

where $\mathrm{C}_{\mathrm{OA}_{0}}$ and $\mathrm{C}_{\mathrm{M}_{0}}$ refer to initial concentrations of oleic acid and methyl alcohol and $\mathrm{K}_{\mathrm{A}}$ refers to adsorption equilibrium constant, and described in terms of conversion of oleic acid as follows:

$$
-\mathrm{r}_{\mathrm{OA}_{0}}=\frac{\mathrm{N}_{\mathrm{A}_{0}}}{\mathrm{~W}} \frac{\mathrm{dX}}{\mathrm{dt}}
$$

where $\mathrm{N}_{\mathrm{A}_{0}}$ and $\mathrm{w}$ refer to initial mole amount of oleic acid and the mass of catalyst, respectively. To test the validity of this mechanism, the conversions of oleic acid as a function of time were plotted for 10:1, 20:1 and 30:1 mole ratios of methyl alcohol to oleic acid (Figure 11 a-c) and $d X_{A} / d t$ values were determined from the slope. Then, the initial rates $\left(-\mathrm{r}_{\mathrm{OA}_{0}}\right)$ were determined for each mole ratio by using equation (3) and the values are given in Table 1. Equation (2) can be reorganized as follows:

$$
\frac{\mathrm{C}_{\mathrm{OA}_{0}} \mathrm{C}_{\mathrm{M}_{0}}}{-\mathrm{r}_{\mathrm{OA}_{0}}}=\frac{1}{\mathrm{k}}+\left(\frac{\mathrm{K}_{\mathrm{A}}}{\mathrm{k}}\right) \mathrm{C}_{\mathrm{M}_{0}}
$$

In Figure $12 \mathrm{a}-\mathrm{c}$, the plots of $-\ln (1-\mathrm{X})$ versus time were presented with linear equation and regression coefficients. As it is seen from the Figure 12, the pseudo-first order homogeneous mechanisms were fitted

\begin{tabular}{|c|c|c|c|c|}
\hline $\begin{array}{c}\mathrm{M}_{0} / \mathrm{OA}_{0} \text { Mole Ratio } \\
(\mathrm{mol} / \mathrm{mol})\end{array}$ & $\begin{array}{l}\mathrm{N}_{\mathrm{M} 0} \\
(\mathrm{~mol})\end{array}$ & $\begin{array}{l}\mathrm{C}_{\mathrm{M0}} \\
(\mathrm{M})\end{array}$ & $\begin{array}{c}\text { COA0 } \\
(\mathrm{M})\end{array}$ & $\begin{array}{c}-r_{O A 0} \\
\left(\mathrm{~mol} \mathrm{~g} \mathrm{cal}^{-1} \mathrm{~min}^{-1}\right)\end{array}$ \\
\hline $10: 1$ & 0.501 & 1.381 & 13.886 & 0.00249 \\
\hline $20: 1$ & 1.001 & 0.885 & 17.775 & 0.00183 \\
\hline $30: 1$ & 1.504 & 0.650 & 19.618 & 0.00142 \\
\hline
\end{tabular}
well with the kinetic data as the mole ratio of methyl alcohol to oleic acid increases.

Table 1. Reaction parameters ${ }^{1}$ and initial reaction rates

${ }^{1} \mathrm{NOA}=0.05 \mathrm{~mol}, \mathrm{~T}=60{ }^{\circ} \mathrm{C}$, catalyst $=0.25 \mathrm{~g}(2.5 \%$ weight, $\mathrm{M}:$ Methanol, OA: Oleic Acid $)$

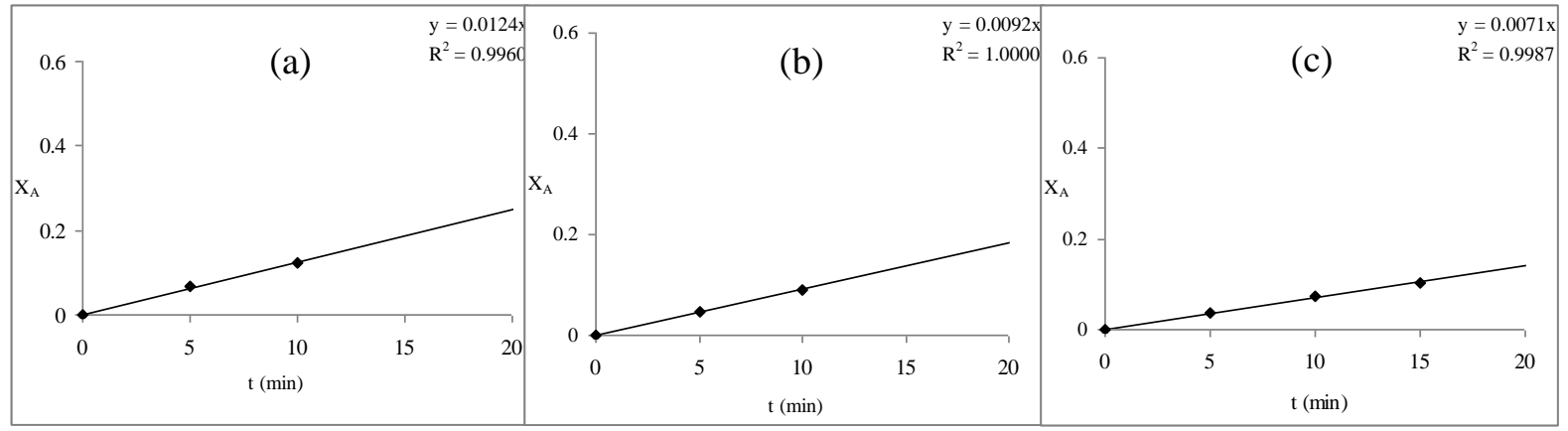

Figure 11. Oleic acid conversion versus time for different mole ratio (alcohol/acid), 10:1 (a), 20:1 (b), 30:1 (c). (catalyst amount: $0.25 \mathrm{~g}$, temperature: $60^{\circ} \mathrm{C}$ ) 


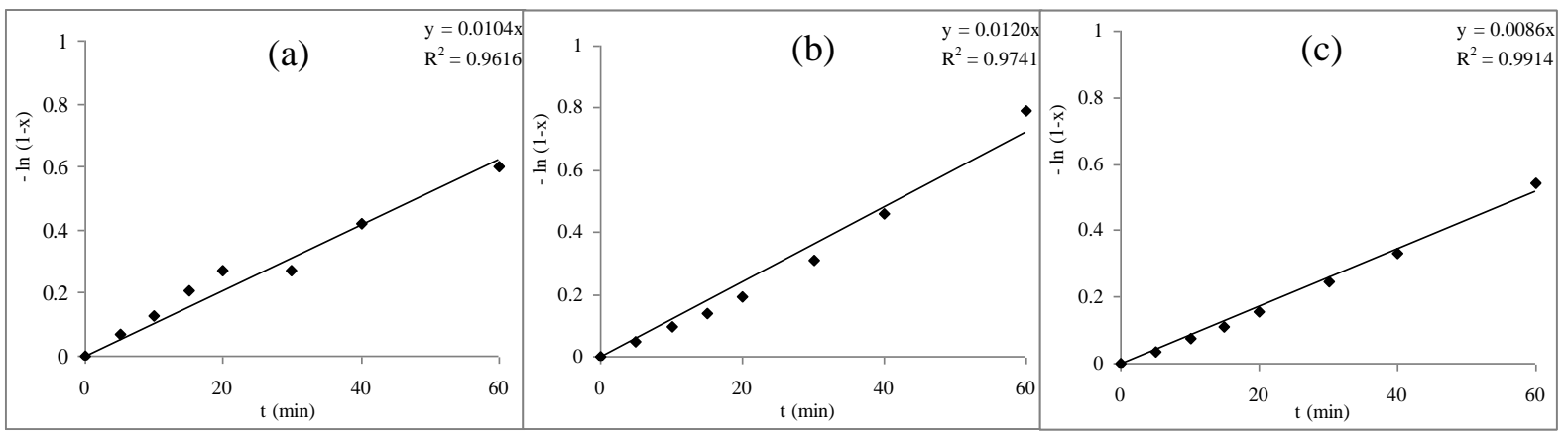

Figure 12. Application of the pseudo-first-order homogenous model for different mole ratios (alcohol/acid), 10:1 (a), 20:1 (b), 30:1 (c). (catalyst amount: $0.25 \mathrm{~g}$, temperature: $60^{\circ} \mathrm{C}$ )

The graphic drown according to Equation (4) was shown in Figure 13. When we compare the correlation coefficients of Eley-Rideal and pseudo-first order homogeneous mechanism, we deduced that Eley-Rideal mechanism in which surface reaction was supposed to be the rate limiting step is more suitable than pseudo-homogeneous model. The rate and the adsorption constants were calculated as $2.057 \times 10^{-4} \mathrm{~L}^{2} \mathrm{~mol}^{-1} \mathrm{~g}^{-1} \mathrm{~min}^{-1}$ and $0.044 \mathrm{~L} \mathrm{~mol}^{-1}$, respectively.

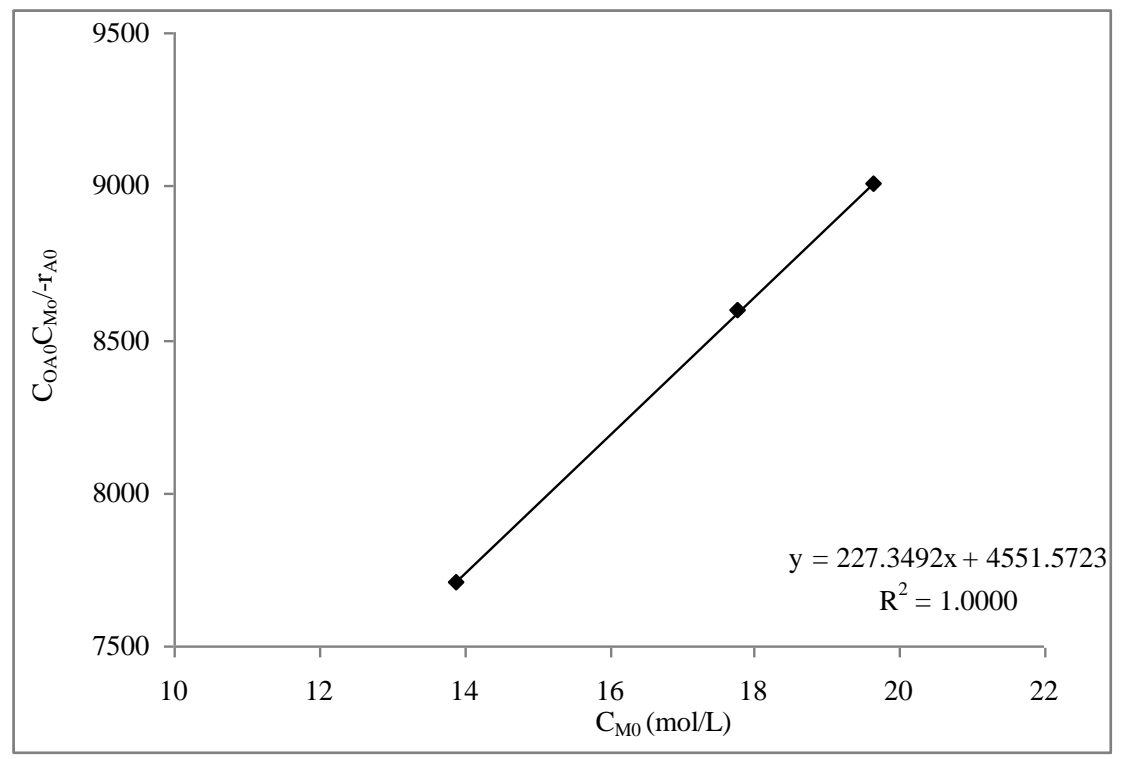

Figure 13. Application of the Eley-Rideal model. (catalyst amount: $0.25 \mathrm{~g}$, temperature: $60^{\circ} \mathrm{C}$ )

\section{CONCLUSION}

In this study, spFe $\mathrm{O}_{4} @ \mathrm{SBA}-15 @ \mathrm{HPW}$ nanocomposite was successfully fabricated through the threestep process. Firstly, $\mathrm{spFe}_{3} \mathrm{O}_{4}$ nanoparticles were prepared by co-precipitation process between $\mathrm{FeCl}_{3} \cdot 6 \mathrm{H}_{2} \mathrm{O}$ and $\mathrm{FeCl}_{2} \cdot 4 \mathrm{H}_{2} \mathrm{O}$ in $\mathrm{HCl}$ solution. Secondly, spFe $\mathrm{O}_{4} @ \mathrm{SBA}-15$ particles were generated by reinforcing $\mathrm{spFe}_{3} \mathrm{O}_{4}$ nanoparticles during SBA-15 synthesis. To obtain open pores, particles were heated up to $500{ }^{\circ} \mathrm{C}$. Finally, $\mathrm{spFe}_{3} \mathrm{O}_{4} @ \mathrm{SBA}-15$ particles were actively functionalized with HPW. The nanocomposite was characterized by XRD, FT-IR, VSM, TEM and SEM/EDX techniques to express the structural, morphological and magnetic properties. From the XRD patterns and FT-IR spectra, it can be said that $\mathrm{spFe}_{3} \mathrm{O}_{4}$ nanoparticles were successfully reinforced into the SBA-15 and TEM and SEM/EDX results supported to the incorporation of HPW in $\mathrm{spFe}_{3} \mathrm{O}_{4} @ \mathrm{SBA}-15$ and the magnetic character of $\mathrm{spFe}_{3} \mathrm{O}_{4} @$ SBA-15@HPWwas confirmed by VSM. 
The nanocomposite was tested as catalyst in esterification reaction between oleic acid and methyl alcohol at different parameters. Also, its performance was compared with Amberlyst-15, Dowex 50Wx4 and HPW catalysts in esterification of oleic acid with methyl alcohol (250 mg, 20:1 (methyl alcohol:oleic acid), $60{ }^{\circ} \mathrm{C}, 24 \mathrm{~h}$ ). Presence of the $\mathrm{spFe}_{3} \mathrm{O}_{4} @ \mathrm{SBA}-15 @ \mathrm{HPW}$, Amberlyst-15, Dowex 50Wx4 and HPW catalysts, the methyl oleate yields achieved to $95.5 \%, 61.7 \%, 48.2 \%$ and $95.3 \%$, respectively. Catalytic activity of $\mathrm{spFe}_{3} \mathrm{O}_{4} @ \mathrm{SBA}-15 @ \mathrm{HPW}$ is higher than that of Amberlyst-15 and Dowex 50Wx4. Moreover the catalytic activities of spFe $3 \mathrm{O}_{4} @ \mathrm{SBA}-15 @ \mathrm{HPW}$ and HPW alone are almost the same, which overcomes the corrosion and insufficient reuse problems of homogeneous catalysts. $\mathrm{spFe}_{3} \mathrm{O}_{4} @ \mathrm{SBA}-15 @ \mathrm{HPW}$ nanocomposite can be easily separated from the reaction mixture magnetically and reused four times without any significant loss on its activity, furthermore, it is safer in terms of toxicity and more environmental acceptability than other conventional catalyst.

\section{REFERENCES}

[1] Chen Y, Cao Y, Suo Y, Zheng G P, Guan X X, Zheng X C. Mesoporous solid acid catalysts of 12-tungstosilicic acid anchored to SBA-15: Characterization and catalytic properties for esterification of oleic acid with methanol. J Taiwan Inst Chem E 2015; 51: 186-192.

[2] Kozhevnikov I V, Kloetstra K R, Sinnema A, Zandbergen H W, van Bekkum H. Study of catalysts comprising heteropoly acid $\mathrm{H}_{3} \mathrm{PW}_{12} \mathrm{O}_{40}$ supported on MCM-41 molecular sieve and amorphous silica. J Mol Catal A Chem 1996; 114: 287-298.

[3] Gagea B C, Lorgouilloux Y, Altintas Y, Jacobs P A, Martens J A. Bifunctional conversion of ndecane over HPW heteropoly acid incorporated into SBA-15 during synthesis. J Catal 2009; 265: 99-108.

[4] Qiu J, Wang G, Zhang Y, Zeng D, Chen Y. Direct synthesis of mesoporous $\mathrm{H}_{3} \mathrm{PMo}_{12} \mathrm{O}_{40} / \mathrm{SiO}_{2}$ and its catalytic performance in oxidative desulfurization of fuel oil. Fuel 2015; 147: 195-202.

[5] Abdalla Z E A, Li B, Tufail A. Direct synthesis of mesoporous $\left(\mathrm{C}_{19} \mathrm{H}_{42} \mathrm{~N}\right)_{4} \mathrm{H}_{3}\left(\mathrm{PW}_{11} \mathrm{O}_{39}\right) / \mathrm{SiO}_{2}$ and its catalytic performance in oxidative desulfurization. Colloids Surf A Physicochem Eng Asp 2009; 341: 86-92.

[6] Yan X M, Mei Z, Mei P, Yang Q. Self-assembled HPW/silica-alumina mesoporous nanocomposite as catalysts for oxidative desulfurization of fuel oil. J Porous Mater 2014; 21 : 729-737.

[7] Wang X S, Huang Y B, Lin Z J, Cao R. Phosphotungstic acid encapsulated in the mesocages of amine-functionalized metal-organic frameworks for catalytic oxidative desulfurization. Dalton Trans 2014; 43: 11950-11958.

[8] Yue D, Lei J, Peng Y, Li J, Du X. Hierarchical ordered meso/macroporous $\mathrm{H}_{3} \mathrm{PW}_{12} \mathrm{O}_{40} / \mathrm{SiO}_{2}$ catalysts with superior oxidative desulfurization activity. J Porous Mater 2018; 25: 727-734.

[9] Patil C R, Rode C V. Synthesis of diesel additives from fructose over PWA/SBA-15 catalyst. Fuel 2018; 217: 38-44.

[10] Li S, Zhai S R, Zhang J M, Xiao Z Y, An Q D, Li M H, Song X W. Magnetic and Stable $\mathrm{H}_{3} \mathrm{PW}_{12} \mathrm{O}_{40}$-Based Core@shell Nanomaterial towards the Esterification of Oleic Acid with Methanol. Eur J Inorg Chem 2013; 5428-5435. 
[11] Kralj S, Makovec D, Campelj S, Drofenik M. Producing ultra-thin silica coatings on iron-oxide nanoparticles to improve their surface reactivity. J Magn Magn Mater 2010; 322: 1847-1853.

[12] Mrowczynski R, Nan A, Liebscher J. Magnetic nanoparticle-supported organocatalysts-an efficient way of recycling and reuse. RSC Adv 2014; 4: 5927-5952.

[13] Wang Y T, Fang Z, Yang X X. Biodiesel production from high acid value oils with a highly active and stable bifunctional magnetic acid. Appl Energy 2017; 204: 702-714.

[14] Hoo P Y, Abdullah A Z. Direct synthesis of mesoporous 12-tungstophosphoric acid SBA-15 catalyst for selective esterification of glycerol and lauric acid to monolaurate. Chem Eng J 2014; 250: 274-287.

[15] Li B, Ma W, Liu J, Han C, Zuo S, Li X. Synthesis of the well-ordered hexagonal mesoporous silicate incorporated with phosphotungstic acid through a novel method and its catalytic performance on the oxidative desulfurization reaction. Catal Commun 2011; 13: 101-105.

[16] Souza K C, Salazar-Alvarez G, Ardisson J D, Macedo W A A, Sousa E M B. Mesoporous silicamagnetite nanocomposite synthesized by using a neutral surfactant. Nanotechnology 2008; 19: 185603.

[17] Brahmkhatri V, Patel A. 12-Tungstophosphoric acid anchored to SBA-15: An efficient, environmentally benign reusable catalysts for biodiesel production by esterification of free fatty acids Appl Catal A Gen 2011; 403: 161- 172.

[18] Masteri-Farahani M, Modarres M. Wells-Dawson heteropoly acid immobilized inside the nanocages of SBA-16 with ship-in-a-bottle method: A new recoverable catalyst for the epoxidation of olefins. J Mol Catal A Chem 2016; 417: 81-88.

[19] Chen Y, Zhang X, Dong M, Wu Y, Zheng G, Huang J, Guan X, Zheng X. MCM-41 immobilized 12-silicotungstic acid mesoporous materials: Structural and catalytic properties for esterification of levulinic acid and oleic acid. J Taiwan Inst Chem E 2016; 61: 147-155.

[20] Frattini L, Isaacs M A, Parlett C M A, Wilson K, Kyriakou G. Support enhanced $\alpha$-pinene isomerization over HPW/SBA-15. Appl Catal B Environ 2017; 200: 10-18.

[21] Brigante M, Pecini E, Avena M. Magnetic mesoporous silica for water remediation: Synthesis, characterization and application as adsorbent of molecules and ions of environmental concern. Micro Meso Mater 2016; 230: 1-10.

[22] Groen J C, Peffer L A A, Perez-Ramirez J. Pore size determination in modified micro-and mesoporous materials. Pitfalls and limitations in gas adsorption data analysis. Micro Meso Mater 2003; 60: 1-17.

[23] Fazaeli R, Aliyan H. Production of Biodiesel through Esterification of Palmitic Acid Using 12Tungestoposphoric Acid Supported on Nanocavity of Aluminium Incorporated Mesoporous SBA-15. Russ J Appl Chem 2015; 88: 676-681.

[24] Xiong J, Zhu W, Ding W, Yang L, Chao Y, Li H, Zhu F, Li H. Phosphotungstic Acid Immobilized on Ionic Liquid-Modified SBA-15: Efficient Hydrophobic Heterogeneous Catalyst for Oxidative Desulfurization in Fuel. Ind Eng Chem Res 2014; 53: 19895-19904. 
Erdem and Bilgin / Eskişehir Technical Univ. J. of Sci. and Tech. A-Appl. Sci. and Eng.21 (2)- 2020

[25] Dashtian K, Zare-Dorabei R. Synthesis and characterization of functionalized mesoprous SBA-15 decorated with $\mathrm{Fe}_{3} \mathrm{O}_{4}$ nanoparticles for removal of $\mathrm{Ce}(\mathrm{III})$ ions from aqueous solution: ICP-OES detection and central composite design optimization. J Colloid Interface Sci 2017; 494: 114-123.

[26] Nicola R, Costişor O, Muntean S G, Nistor M A, Putz A M, Ianaşi C, Lazau R, Almasy L, Sacarescu L. Mesoporous magnetic nanocomposites: a promising adsorbent for the removal of dyes from aqueous solutions. J Porous Mater 2020; 27: 413-428.

[27] Ilgen O. Investigation of reaction parameters, kinetics and mechanism of oleic acid esterification with methanol by using Amberlyst 46 as a catalyst. Fuel Process Tech 2014; 124: 134-139. 